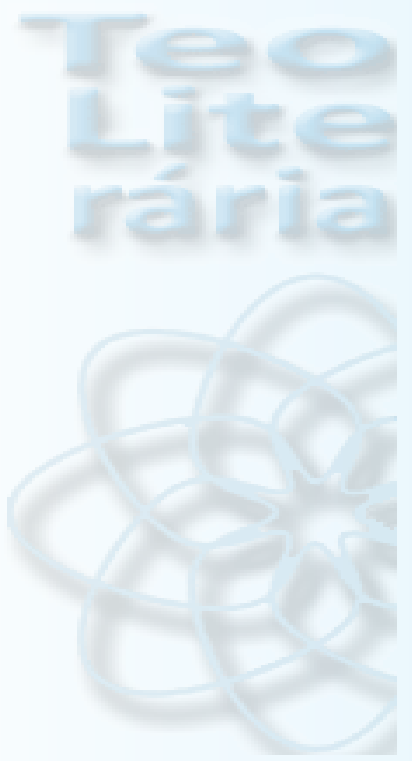

Arquivo enviado em

21/03/2017

e aprovado em

09/06/2017.

V. $7-$ N. $13-2017$

* Doutor em Teologia pelo Instituto Ecumênico de

Pós-Graduação na Escola

Superior de Teologia

em São Leopoldo/RS.

Professor do Mestrado em Patrimônio Cultural e Sociedade na Universidade da Região de Joinville UNIVILLE/SC. Professor de Teologia Sistemática

na FLT, São Bento do

Sul/SC. Publicações

na área da Teologia,

Filosofia, Ética e Bioética. eulerwestphal@gmail.com.

\section{A presença da teologia na \\ cultura: uma interpretação sobre a imaterialidade da cultura}

\author{
The presence of theology in \\ culture: theological aspects \\ of the immaterial culture
}

Euler Renato Westphal*

\section{Resumo}

O autor aborda a questão do lugar da teologia no contexto da tradição positivista do mundo acadêmico brasileiro, o qual deixa a teologia à margem. Observa-se a necessidade de uma discussão crítica sobre o lugar da teologia nas teorias de cultura. $\mathrm{O}$ artigo defende que a espiritualidade é o núcleo e a expressão de uma cultura. A partir disso, constata-se que os conceitos de Weltanschauung (cosmovisão) e Lebensanschauung (visão de vida) são padrões culturais, sistemas de orientação, para que a vida humana seja possível. Essa imaterialidade da cultura possibilita sentido para a vida humana, que revela as relações invisíveis, entretanto, reais de uma espiritualidade. As teias de significados proporcionadas por uma visão teológica organizam a cultura. No processo de secularização, a cultura assume o papel religioso de redenção da natureza pecaminosa do ser humano. A teologia, como 
ciência, tem a tarefa de analisar e interpretar os processos imateriais, ou seja, a espiritualidade de uma cultura.

Palavras-chave: Teologia, Valor Simbólico, Cultura Imaterial, Secularização, Interdisciplinaridade

\section{Abstract}

The author presents the question of theology's place in the context of the positivistic Brazilian academic world, which leaves theology at the margin. The requirement of a critical discussion about the place of the theology in the culture theories is observed. The article defends that spirituality is the core and the expression of a culture. From this, it is acknowledge that the concepts of Weltanschauung (worldview) e Lebensanschauung (lifeview) are cultural patterns, orientation frameworks, to make the human life possible. This immateriality of culture makes meaning to human life possible, which reveals the invisible, however, real, relations of a spirituality. The webs of meaning proportionated by a theological view organize a culture. In the secularization process, culture assumes the religious character of the redemption of the human sinful nature. Theology, as science, has the task to analyze and to interpret the immaterial processes, namely, of the spirituality of a culture.

Keywords: Theology, Symbolic value, Immaterial culture, Secularization, Interdisciplinarity

\section{Introdução}

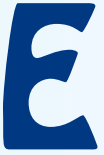

nquanto a teologia tem um lugar de destaque nas universidades europeias, no contexto acadêmico brasileiro, observa-se certa indiferença para com a presença da teologia.A visão positivista da academia brasileira esqueceu aspectos fundamentais das tradições religiosas judaico-cristãs, que moldaram a cultura da modernidade. Observa-se esse desconhecimento em várias publicações. O material de divulgação do Iphan/SC1 reconhece que os colonos de origem ale-

1.Cf. Instituto do patrimônio Histórico Artístico Nacional. Roteiros Nacionais de Imigração - Santa Catarina: preservação do patrimônio cultural. Florianópolis: IPHAN/ 11. Superintendência Regional, 2008. UNESCO. World Heritage Convention. Disponível em:http://whc.unesco.org/ Acesso em: 02 de fevereiro de 2014. 
mã, bem como italianos e imigrantes de outros países europeus, trouxeram as bases culturais para a construção de uma sociedade diferenciada no Brasil do século 19, sem, contudo, descrever o aspecto religioso, espiritual e teológico desses imigrantes. 2 Percebe-se, assim, no meio acadêmico brasileiro, um conceito prévio de que a teologia não pode ser um empreendimento acadêmico, bem como a visão de que a teologia seja um arcaísmo, que precisa ser superado. Essa visão está presente, porque a teologia ainda é vista pelos moldes positivistas (SINNER, 2009; CRUZ, MORI, 2011). Diante do esquecimento (RICOEUR, 2007, p. 404-462) da teologia, pretendemos esboçar uma breve abordagem panorâmica da relação entre teologia, espiritualidade e cultura. Essa relação deverá ser abordada na discussão com autores como Max Weber, Clifford Geertz, Terry Eagleton e Albert Schweitzer.

\section{A cultura e a teologia como teias de significados}

Os sistemas de pensamento e a memória geram desdobramentos que caracterizam a imaterialidade de uma cultura. O mundo das ideias e dos processos mentais produzem as diferentes representações do mundo simbólico. Os sistemas de pensamento proporcionam forma ao mundo simbólico e às relações sociais (RAYNAUT, 2011, p. 93). Também é verdadeiro dizer que os processos da vida social geram múltiplas representações mentais e novos símbolos, em uma mútua e recíproca interpenetração entre o imaterial e o material, o individual e o coletivo (WESTPHAL, 2012, p. 64-65; SELL, BRÜSEKE, 2006).

\footnotetext{
2."A vinda de colonos europeus para o Brasil marcou uma ruptura definitiva com o sistema colonial vigente até então. A distribuição de terras baseada na lógica latifundiária de monoculturas como era o caso das grandes fazendas de café do sudeste ou dos canaviais nordestinos e apoiada na mão-de-obra escrava, passou a ser contraposta por um novo modelo, baseado na pequena propriedade rural, com mão-de-obra familiar e produção diversificada." Roteiros nacionais de imigração - Santa Catarina: Preservação do Patrimônio Cultural. Florianópolis; IPHAN/11. Superintendência Regional, 2008. p. 17. Cf. Fundação Catarinense de Cultura. Cartilha Patrimônio Imaterial. Secretaria de Estado de Turismo, Cultura e Esporte. Governo do Estado de Santa Catarina, s/d. p. 3,15 . Superintendência Regional do IPHAN em Santa Catarina. Roteiros nacionais de imigração de Santa Catarina. Ministério da Cultura - Governo Federal,s/d.
} 
Entendemos que a cultura é fruto de uma espiritualidade, a qual é construída coletivamente a partir de valores individuais, que promovem sentido para a vida humana. Nesse contexto, também observamos que a espiritualidade é o núcleo de uma cultura. Assim, espiritualidade e cultura se entrelaçam, pois uma é condição e possibilidade da outra. A espiritualidade molda uma cultura, que inclui o aspecto religioso. Segundo Tillich, "pois a substância da cultura é a religião e a forma da religião é a cultura" (TILLICH, 1936, p. 235). Em especial, a teologia tem a tarefa de compreender, explicar e propor novas abordagens de redes do simbólico e do religioso que norteiam a vida humana (WEBER, 2004, p. 169-276). Max Weber aborda as questões culturais a partir da teologia, e a cultura protestante é o seu objeto de estudo. Desse modo, a cultura é uma complexa teia de significados para dar sentido e sustentação à vida humana. Weber diz:

Se é que é possível encontrar um objeto que dê algum sentido ao emprego dessa designação, ele só pode ser uma 'individualidade histórica', isto é, um complexo de conexões que se dão na realidade histórica e que nós encadeamos conceitualmente em um todo, do ponto de vista de sua significação cultural (WEBER, 2004, p. 41).

Clifford Geertz assume a cultura como teia de significados de Weber. Segundo Geertz, o ser humano é dependente dos costumes, usos, valores, conjunto de hábitos para que a vida seja possível. Assim, o ser humano precisa de sistemas de orientações que ordenem o seu comportamento. O papel da cultura na vida humana é essencial para dar sustentação e significado à vida.Na análise de Geertz, em cada povo, a dimensão religiosa é fundamental na formação de uma cultura e de seus desdobramentos (GEERTZ, 2011, p. 33). Desse modo, segundo ele, há uma relação entre capacidades inatas de falar e a construção cultural de se aprender um determinado idioma. Construções como as catedrais são expressão da relação entre os seres humanos e Deus, vividas em um momento histórico e determinado por uma sociedade particular. O mundo simbólico dos seres humanos, a exemplo das suas 
crenças religiosas, seus valores morais e sua percepção estética, molda a organização de grupos sociais, bem como servirá de referência para a organização de uma sociedade (GEERTZ, 2011, p. 36). O ser humano precisa das fontes simbólicas para governar o seu comportamento, a fim de ter referências de apoio no mundo em que vive. Trata-se de instruções ou programas imateriais de símbolos significantes. Os padrões culturais colocam o Norte para que a vida seja possível. Caso contrário, os seres humanos e suas sociedades não seriam governáveis. A cultura é o conjunto desses padrões culturais imateriais, que foram construídos ao longo da história. Segundo Geertz, "A cultura, a totalidade acumulada de tais padrões, não é apenas um ornamento da existência humana, mas uma condição essencial para ela - a principal base de sua especificidade" (GEERTZ, 2011, p. 33).

Geertz, fundamentado em Weber, entende que a imaterialidade da cultura é expressão da própria condição humana de dar significado à existência humana (GEERTZ, 2011, p. 96). Portanto, o fundamento da cultura está na sua imaterialidade, na sua espiritualidade, como teia de significados e de sentido, que tem caráter universal. Segundo Geertz,

A necessidade de tal fundamento metafísico para os valores parece variar bastante em intensidade de cultura para a cultura e de indivíduo para indivíduo, mas a tendência de desejar alguma espécie de base fatual para o compromisso de cada um parece praticamente universal - o mero convencionalismo satisfaz a muito poucas pessoas, em qualquer cultura (GEERTZ, 2011, p. 96).

Os conceitos alemães de Weltanschauung (cosmovisão) e Lebensanschauung (visão de vida), utilizados por Geertz, são padrões culturais ou sistemas de orientação, ou seja, sistemas de visão de mundo e sistemas de visão da vida. Segundo Geertz, Weltanschauung e Lebensanschauung são rituais do cotidiano e atividades comuns em uma sociedade. Essa inter-relação entre imaterialidade e espiritualidade adquire significado moral visível, que orienta a vida de uma comunidade (GEERTZ, 2011, p. 14, 73). Para Geertz, "Olhar dimensões simbólicas 
da ação social - arte, religião, ideologia, ciência, lei, moralidade, senso comum - não é afastar-se dos dilemas existenciais da vida em favor de algum domínio empírico de formas não-emocionalizadas; é mergulhar no meio delas" (GEERTZ, 2011, p. 21).

Portanto, a dimensão da imaterialidade da cultura, que é o conjunto de significados de uma espiritualidade, proporciona a construção da realidade social (GEERTZ, 2011, p. 82-83, 87-91). O ser humano somente é viável como criatura se os complexos processos de construção do simbólico estiverem assegurados (GEERTZ, 2011, p. 73). Ao considerar isso, propomo-nos a olhar a questão da imaterialidade da cultura com mais cuidado, a partir de autores que discutem a questão da espiritualidade e da teologia como aspectos que estão presentes na cultura.

\section{Teologia e ética enquanto Lebensführung}

A relação entre ética e cultura é importante na construção deste sistema de símbolos. A Weltanschauung da cultura protestante e da modernidade, discutida por Max Weber, está ligada à teologia. Assim, pretendemos olhar com mais cuidado para a interpretação de Weber, anunciada anteriormente, sobre a sociologia da religião, o espírito do capitalismo, bem como sobre a questão da cultura e do ethos protestante. Segundo Weber, cultura é uma Lebensführung, ou seja, a condução de vida, que está próxima à Lebensanschauung, que é a visão de vida (PIERUCCI, 2004, p. 7; SELL, 2006, p. 166-221). Isso fica claro na discussão de Weber, nas notas de rodapé, com os teólogos de sua época (WEBER, 2004, p. 169-276). As questões teológicas do protestantismo são fundamentais para a concepção cultural do trabalho, do progresso e do enriquecimento material. Segundo Weber, ao comparar a tradição católica, que formou preferencialmente artesãos, com a protestante, cujos membros ocupam, em boa medida, funções qualificadas nas indústrias, diz que as concepções teológicas são determinantes para a construção de uma cultura das sociedades protestantes. Assim, Weber aborda as 
raízes espirituais da Weltanschauung e da Lebensanschauung protestantes. Desse modo, espiritualidade e cultura se condicionam em relações de frutificação recíproca. Weber diz:

Nesses casos, a relação de causalidade repousa sem dúvida no fato de que a peculiaridade espiritual inculcada pela educação, e aqui vale dizer, a direção conferida à educação pela atmosfera religiosa da região de origem e da casa paterna, determinou a escolha da profissão e o subsequente destino profissional (WEBER, 2004, p. 33).

Essa espiritualidade distinta entre católicos e protestantes, constatada por Weber, se deve pela educação que receberam em sua região de origem, católica ou protestante, e pela casa paterna na qual se vivenciava a educação e a espiritualidade, católica ou protestante. Assim, o conceito espírito (do capitalismo) (WEBER, 2004, p. 41) expressa inúmeras conexões complexas de um processo histórico, que Weber chama de significação cultural. $O$ espírito é também a ética do dever para com os compromissos com o outro, que priorizam a honestidade, a pontualidade, a presteza, a modéstia e a simplicidade. Decorrente desses valores se estabelecem possibilidades de prosperidade material. Assim, a utilidade econômica é vista como virtude ética na tradição protestante (WEBER, 2004, p. 44-46).

Para dar sustentação à ideia da significação cultural protestante, Weber discute a questão da cultura e do protestantismo a partir do conceito de vocação. A palavra Beruf (profissão) tem a ver com a missão que Deus concede ao ser humano, que se encontra nos povos de tradição protestante. Nesse sentido, Lutero trouxe uma contribuição nova, também para o contexto profano e secularizado, da ideia de Beruf. A profissão é uma missão de vida para o cristão. Essa concepção de missão, em Lutero, segundo Weber, perpassa a vida do indivíduo na totalidade, incluindo as suas atividades profissionais ligadas ao mundo. $\mathrm{O}$ amor a Deus é vivido pelo cristão na relação com o próximo, por meio de sua profissão. Esta é decorrente de uma Berufung, um chamado religioso 
(WEBER, 2004, p. 71-73)3. Para Lutero, segundo Weber, a atividade profissional seria uma ordem de Deus, por meio da qual, o cristão vive a sua missão, o seu chamado. Esse chamado de Deus é exercido nas profissões do mundo e não no âmbito do religioso, ou seja, de uma igreja institucional (WEBER, 2004, p. 76-77)4. A preocupação de Weber é demonstrar o impacto da teologia da Reforma no processo de desenvolvimento da cultura moderna. O foco da construção de vida na imanência e na materialidade, tão característica da cultura moderna, é uma decorrência da secularização da teologia protestante. Viver o chamado nas profissões do mundo, a exemplo do marceneiro, carpinteiro, agricultor, das profissões técnicas, do engenheiro, administrador, são desdobramentos de "influxos da Reforma", como diz Weber (WEBER, 2004, p. 82-83) 5 . Nesse sentido, Norbert Elias corrobora a cultura como Weltanschauung assim:

Max Weber [...] denominou uma 'formação de consciência protestante': a construção de um mecanismo de autocontrole, com a ajuda do qual uma pessoa, completamente sozinha, estava capacitada a orientar suas próprias ações - seja o que for que as pessoas digam - para decidir por si mesma e ser responsável somente perante sua consciência e seu Deus (ELIAS, 1997, p. 95).

A partir disso, observamos que Weber percebeu que a cultura da modernidade recebeu sua influência, em grande medida, do pensamento da

3.Lutero interpreta o apóstolo Paulo dizendo que somos livres para exercer todas as profissões, como expressão do amor ao próximo. Para Lutero, votos monásticos e a proibição do matrimônio devem ser condenados (WEBER, 2004, Nota 69, p. 197).

4.Weber rejeita a ideia de que o espírito do capitalismo seja uma consequência única da Reforma, pois o capitalismo é mais antigo do que a Reforma. Para ele, isso é "uma tese tão disparatadamente doutrinária" (WEBER, 2004, p. 82). Weber se queixa sobre a interpretação dogmática de seu pensamento: "Justo essa é a tese que curiosamente não cessam de me atribuir sempre de novo, apesar dessa observação e das outras a seguir, que permanecem inalteradas por serem, a meu juízo, suficientemente claras" (WEBER, 2004, Nota 84, p. 204).

5.Para Weber, a ética e cultura da honestidade, do cuidado com os bens pessoais, a sinceridade e o fato de não fazer dívidas no protestantismo são as mesmas virtudes valorizadas e exigidas nas empresas e instituições nos Estados Unidos (WEBER, 1999, p. 365-408). 
Reforma protestante. Portanto, a Reforma proporcionou uma consciência protestante, que poderíamos denominar de Weltanschauung, a qual influenciou significativamente a secularização da modernidade. Ou seja, a Weltanschauung da modernidade teve influxos do Protestantismo. Ao ouvir a interpretação sobre Lutero, nada melhor do que ouvir o próprio reformador. Lutero dizia que o cristão vive para os outros e serve aos outros. No serviço ao próximo é que ele serve a Deus. A vocação religiosa é vivida em ações concretas, por meio das profissões existentes na época, para que a vida do próximo fosse melhorada materialmente. Lutero dizia que,

a pessoa não vive somente para si mesma neste corpo mortal, para operar nele, mas também para todas as pessoas na terra, sim, ela vive somente para os outros, e não para si. Pois para isso sujeita seu corpo, para assim poder servir a outros com mais sinceridade e liberdade (LUTERO, 1989, p. 451).

Para Lutero, nossas obras não servem para servir a Deus, mas são executadas para o bem do próximo. Nesse sentido, a visão medieval da negação do corpo em benefício da alma é superada. O corpo é um meio pelo qual o irmão fraco possa ser auxiliado materialmente. Lutero afirma essa disposição ao trabalho como vocação assim,

$E$ nesse mesmo sentido também é cristão cuidar do corpo, para que, por meio de seu vigor e bem-estar, possamos trabalhar, adquirir bens e preservá-los para subsídio daqueles que têm carência, para que assim o membro robusto sirva ao membro fraco, e sejamos fiIhos de Deus, um preocupado e trabalhando pelo outro, carregando os fardos uns dos outros e assim cumprindo a lei de Cristo (LUTERO, 1989, p. 452).

Diante dessas considerações, pergunta-se como a condução de vida (Lebensführung) está ligada à ética protestante e é formadora de uma cosmovisão (Weltanschauung) e visão de vida (Lebensanschauung) que promove cultura? 


\section{Ética e cultura como processo de humanização}

Como vimos, Lutero coloca a vocação em um plano intramundano, desobrigando o cristão do seu compromisso religioso institucional. A vocação de Deus para o cristão é vivida no mundo concreto, com suas possibilidades e ambiguidades, por meio de sua profissão. É bom lembrar que a materialidade da fé em Cristo e suas consequências são surpreendentemente intramundanas. Soa como algo escandalosamente profano quando Lutero aconselha que se viva a fé cristã no mundo de tal forma, como se Deus não existisse (BAYER, 1995, p. 73). Observamos que Albert Schweitzer, teólogo protestante, filósofo, médico e músico, aborda a relação entre ética, cultura e Weltanschauung em uma perspectiva quase que totalmente intramundana (SCHWEITZER, 1996, p. 85) ${ }^{6}$. Para ele, o futuro da cultura somente é possível se houver uma concepção em que o mundo e a vida sejam afirmados, e que a ética leve ao aperfeiçoamento das ações humanas. As ativas relações entre Weltanschauung e ética geram cultura. A Weltanschauung precisa produzir uma visão que afirme positivamente a realidade do mundo (SCHWEITZER, 1996, p. 72-73).

Schweitzer, ao estabelecer relações entre a ética, a cultura e a Weltanschauung, critica a visão racionalista do lluminismo, que não considerou suficientemente aspectos éticos. As grandes convicções que nortearam a humanidade são destruídas e, em lugar delas, novas concepções, reduzidas, de leitura da realidade não proporcionam mecanismos de agregação da sociedade. Na modernidade, a consciência de realidade é construída pela noção de utilidade (SCHWEITZER, 1996, p. 38-40). Segundo Schweitzer, para superar a racionalidade mecânica da modernidade, é necessário criar uma Weltanschauung que proporcione valores para a vida. A Weltanschauung precisa se concretizar por meio da ética. A ética se torna parte da Weltanschauung, e ambas, ética e Weltanschauung, produzirão cultura. Dessa forma, deverá haver um processo de afirmação da vida e do mundo, que afirma a dignidade e o

6.Para Schweitzer, "o essencial do processo de pensar é a luta pela cosmovisão" (SCHWEITZER, 1995, p. 85). 
valor intrínseco da vida e da cultura. A ética está dirigida para o aperfeiçoamento humano, para a consumação e a coroação da vida humana (SCHWEITZER, 1996, p. 71-73). Além disso, a ética é condição e possibilidade no processo de humanização da cultura (SCHWEITZER, 1996, p. 27-28). Nesse contexto, coloca-se a questão sobre a relação entre a espiritualidade cristã e a cultura em um mundo secularizado. Schweitzer vê o cristianismo como possibilidade de transformar a cosmovisão pessimista em uma otimista, à medida que a religião de Jesus se colocar contra a religião do dogma (SCHWEITZER, 1996, p. 159, 332-333). Esse otimismo pode ser vivido na reverência diante da vida. Para Schweitzer, "Ética é a responsabilidade ampliada e sem limites em relação a tudo o que vive" (SCHWEITZER, 1996, p. 332).

A visão intramundana de Lutero, de que se deve viver no mundo como seu Deus não existisse, é encontrada em Schweitzer. Chama atenção que, nas abordagens de Schweitzer, a ética e a cultura não precisam, necessariamente, fazer menção ao âmbito da eternidade. A ética acontece na vida imanente. Assim, a reverência diante da vida é a forma de o ser humano ser fiel a si mesmo. Esse é um exemplo teórico de como acontece o processo de secularização da cultura na modernidade, no contexto da teologia protestante. Em Schweitzer, percebe-se a busca pela vivência ética radical, pela reverência diante da vida como uma forma de despertar a paz eterna com perspectivas de uma paz escatológica. A Lebensanschauung e a Weltanschauung, que tem a reverência diante de todas as formas de vida como propósito da existência cristã, trazem perspectivas salvíficas de uma paz eterna, reduzida ao âmbito da vida imanente (SCHWEITZER, 1996, p. 368).

\section{A redenção secularizada}

A espiritualidade da cultura é um tema que perpassa as relações humanas e a sobrevivência dos seres humanos, pois é um importante dispositivo para que a maldade humana seja controlada. Somos lembrados 
do uso político, civil da lei, que foi enfatizado pela Reforma protestante, como recurso teórico para falar do governo de Deus no mundo. A função do uso político, que é o primeiro uso da lei, tem como objetivo a preservação da vida no mundo e para que a maldade humana seja limitada nas suas ações destruidoras. Dessa forma, a cultura, palavra que Lutero ainda não conhecia, que é formada pela razão, linguagem, família, Estado e pelo trabalho, é o modo pelo qual Deus governa o mundo. Trata-se de uma espiritualidade que se torna concreta na vivência do amor ao próximo (BAYER, 1995, p. 89-93; FORELL, 1985, p. 97-109).

Eagleton aponta para as relações multifacetadas da cultura em seus aspectos espirituais, pois cultura é transformar a natureza humana por meio do cultivo e do cuidado em uma dimensão espiritual (EAGLETON, 2005 , p. 15). Para ele, ao contrário de Lutero, a cultura, semelhantemente à graça, precisa cooperar com a natureza para alcançar a superação da "nossa natureza perversa". Assim como a graça, também a cultura é um potencial para que o ser humano se enleve "à graça da cultura." Segundo Eagleton, "Se existe uma história e uma política ocultas na palavra 'cultura', há também uma teologia” (EAGLETON, 2005, p. 16). O conceito de cultura se amplia para o Estado, a ética e o processo de humanização das pessoas. Entretanto, a cultura, a ética, o Estado e a humanização não estão colocados em setores compartimentalizados, mas um aspecto está interligado ao outro em um processo de frutificação mútua. Para Eagleton, há uma teologia e uma espiritualidade necessária presente na cultura e no Estado. O conceito de cultura como o conceito Bildung, que priorizava a memória, a sensibilidade, o holístico e o orgânico, vem a partir de Herder e de Schiller, ou seja, do romantismo alemão (EAGLETON, 2005, p. 16). ${ }^{7}$ Nesse processo de secularização da redenção cristã, o cultivo tem a função de refinamento do ser humano, transformando os egos rebeldes em pessoas transformadas pelo sujeito universal. Ou seja, o estado da natureza, do pecado, é transformado pela graça. A graça seria a cultura. A função do Estado seria a de

7.Esta relação entre cultura e o romantismo foi aprofundada por Winkler, 2012, p. 13-53. 
garantir a presença do universal na sociedade civil (EAGLETON, 2005, p. 16-19). O Estado teria a função de proporcionar as possibilidades e as condições para o cultivo humano, que é um espaço de vivência de espiritualidade, sem as referências religiosas. Ou seja, a redenção secularizada é necessária para que o Estado cumpra com a sua tarefa. Segundo Eagleton, "para que o Estado floresça, precisa incutir em seus cidadãos os tipos adequados de disposição espiritual; e é isso o que a ideia de cultura ou Bildung significa numa venerável tradição de Schiller a Matthew Arnold" (EAGLETON, 2005, p. 16). Nesse processo, a cultura e a ética se condicionam e têm como objetivo desenvolver a natureza humana em sua noção de homem e buscar a vivência de cidadania. Assim, segundo Eagleton, o desenvolvimento da boa índole, ou seja, a elevação da "natureza perversa" "para a graça da cultura" é mediada pela "pedagogia ética". Qual seria a função do Estado nesse processo? A espiritualidade da cultura deve ser incentivada pelo Estado aos seus cidadãos. O Estado é a encarnação do universal na sociedade civil. $O$ indivíduo, que é representado pelo Estado, é a corporificação do ideal da humanidade. Para Eagleton, a materialização dessa espiritualidade se encontraria no Estado, que transforma homens, indivíduos, em cidadãos responsáveis, reconciliando harmoniosamente as fraturas da sociedade. O modernismo precisa de Deus como parte integrante de suas narrativas de cultura (EAGLETON, 2005, p. 16-17, 29). O pós-modernismo despreza a tradição e as conquistas sociais, a solidariedade e os interesses coletivos, bem como as narrativas da modernidade. $O$ que vale é a particularização, assim, é o particular que toma o lugar do universal. A dimensão da espiritualidade cristã contida na organização do Estado e nas pedagogias éticas é diluída em posturas que negam a existência do outro nas novas formas de fundamentalismo e de fascismo (EAGLETON, 2005, p. 105-110). Decorrente dessas observações, segundo Terry Eagleton, "numa interação em três frentes, a cultura como espiritualidade é corroída pela cultura como mercadoria, para dar origem à cultura como identidade" (EAGLETON, 2005, p. 106). 
Entendemos que os conceitos teológicos da história da salvação e as duas naturezas de Cristo, bem como o escândalo da cruz e a morte de Cristo, que vence o Diabo, são transformados, pela pós-modernidade, em cultura e ética imorais. Para Maffesoli, essa ética imoral conhece os rituais de inversão, nos quais, os bacanais assumem um lugar central. Também a cultura da pós-modernidade não consegue fugir de suas contingências teológicas cristãs, mesmo negando ou invertendo-as (MAFFESOLI, 2004, p. 91-97; MAFFESOLI, 2005). Assim, não há mais pecado e nem redenção, pois "a transgressão da lei é uma forma de caminhar para a salvação" (MAFFESOLI, 2004, p. 92). A transgressão e as vivências orgíacas foram transformadas em formas de redenção. Desse modo, tanto os processos de inversão moral e de sincretismo religioso, bem como a noção de igualdade e diversidade cultural e religiosa, fundamentam-se na tradição cristã. Maffesoli chama a atenção para a doutrina da Trindade, bem como para a doutrina das duas naturezas de Cristo, como fundamento teológico para as dissoluções éticas e o relativismo cultural na pós-modernidade (MAFFESOLI, 2004, p. 91-110; VATTIMO, 2002).

De modo semelhante a Maffesoli, em Eagleton, temos uma abordagem da redenção secularizada. A cultura está tomada de valores teológicos e de percepções soteriológicas. Por meio da cultura, o ser humano passa a receber sua identidade. $\mathrm{Na}$ análise de Eagleton, o ser humano pós-moderno tem consciência da maldade humana e do pecado. Lutero também apontou para a radicalidade da maldade humana na sua discussão com Erasmo de Roterdam. Para Lutero, ao contrário de Eagleton, a redenção não vem pela cultura, mas vem pela morte de cruz do Deus encarnado, que é Jesus Cristo. Eagleton, por sua vez, não faz alusão a Lutero, mas reinterpreta o pensamento de natureza e de graça da concepção católica (LUTERO, 1993, p. 11-216; WA 18, p. 600-787; 1989, p. 97-170; WA 6, p. 202-276). De qualquer forma, a teoria da cultura, em Eagleton, está permeada pela concepção teológica, reduzida, é verdade, ao âmbito das contingências humanas e sociais, ressignificando o 
aspecto da redenção de Deus por meio de Cristo.

\section{Considerações finais}

A partir dos autores acima analisados, a cultura vive de referências imateriais, religiosas e salvíficas, mesmo que não de forma explícita e consciente. A cosmovisão teológica se exterioriza no modo como a sociedade é organizada. Sendo assim, a religião é a sustentação de uma cultura, que se articula por meio da racionalização, que é verbalizada pelo discurso teológico (TILLICH, 1959). A fala teológica acadêmica tem a função de colocar em evidência as teias de significado e o valor simbólico, que ocorre por meio da racionalização dos processos de significados e de sentido que nutrem os arranjos culturais (PASSOS, 2009, p. 4-5) ${ }^{8}$. Nesse contexto, é necessário distinguir religião e teologia. A intenção é de colocar a teologia no cenário da cultura, que é o nosso tema. A dimensão da fé em Deus e da confissão cristã, em Jesus Cristo, trouxe consequências e moldou aspectos culturais, em especial, no ocidente, a exemplo da economia, da música, da alfabetização e da criação de escolas para a formação de profissões de mão de obra qualificada, como diríamos hoje (WA 15, p. 48; LUTERO, 1995, p. 321). O filósofo existencialista Karl Jaspers diz: "Os conteúdos da filosofia ocidental não têm somente suas fontes históricas no pensamento grego, mas também no pensamento bíblico" (JASPERS, 1948, p. 37). Assim, para esse médico psiquiatra e Prêmio Nobel de literatura, o estudo da Bíblia serviu de fundamento para a filosofia, a sociologia, a economia e teorias políticas até os dias de hoje.

A tese em discussão é que a teologia proporciona uma teia de significados para que a cultura e seus patrimônios sejam possíveis. Falar de teologia significa falar também de um mundo simbólico que proporciona vínculos como família, religião, valores, proporcionando identida-

8.Passos também fala da questão pública da teologia, bem como da noção do logos e da necessidade de se falar de transcendência na teologia, que é negada pelo Parecer $118 / 2009$. 
des históricas e sociais fundamentais, como o sentimento de pertença nas relações intersubjetivas de uma sociedade. A teologia, como ciência, procura analisar e entender as Weltanschauung e Lebensanschauung de uma cultura, que está permeada pelo religioso. A sociologia analisa as teias sociológicas e a economia, as dinâmicas econômicas. De modo semelhante, a teologia analisa os processos teológicos existentes na religião, na sociologia ou na economia. Encontramos essa interpretação teológica da cultura, da sociologia e da economia em Geertz, Eagleton, Schweitzer e, em especial, em Weber.

A teologia poderá elucidar as teias de valores e o sistema de crenças que sustentam uma determinada cultura. $O$ que a teologia tem a nos dizer a respeito da cultura, como expressão da vida humana, considerando que ela desencadeou processos de mudanças culturais? A pergunta norteadora é sobre a relação entre teologia e cultura. A teologia, enquanto ciência, é um instrumento importante na compreensão das teias de significados de uma cultura, que é formada pela Lebensanschauung e Weltanschauung de uma sociedade. Os influxos da cosmovisão protestante determinaram significativamente a cultura moderna. Assim, a cultura é um produto do processo de humanização, necessária para que o mal seja superado por meio dela. Entretanto, a cultura não tem somente o seu aspecto de humanização. Ela carrega em si um potencial de conflito e de agressões.

Guerras são declaradas em nome de uma cultura. Embora a questão da ambiguidade das culturas não tenha sido tematizada neste artigo, faz-se necessário apontar para o potencial destruidor das culturas. Na compreensão protestante, o ser humano é completamente escravo do pecado e de forças destruidoras, que perpassam as culturas. $O$ pecado, como mal radical, está presente em todas as construções culturais, incluindo o mundo religioso e as igrejas (WINKLER, 2012, p. 13-53; EAGLETON, 2005, p. 51-77) $)^{9}$. A teologia tem, a partir do primeiro uso 
da lei, a função de identificar aspectos destruidores da cultura e propor meios de superação para que a vida seja possível. Assim, cultura e teologia não são companheiros estranhos, mas expressões distintas da condição humana.

\section{Referências}

BAYER, Oswald. Freiheit als Antwort. Tübingen: J.C.B. Mohr, 1995.

BAYER, Oswald. A teologia de Martim Lutero: uma atualização. Trad. Nélio Schneider. São Leopoldo: Sinodal, 2007.

CRUZ, Eduardo R. da; MORI, Geraldo De (Orgs). Teologia e Ciências da Religião: a caminho da maioridade acadêmica no Brasil. São Paulo; Belo Horizonte: Paulinas; Ed. PUCMinas, 2011.

EAGLETON, Terry. A idéia da cultura. São Paulo: UNESP, 2005.

ELIAS, Norbert. Os alemães: a luta pelo poder e a evolução do habitus nos séculos XIX e XX. Rio de Janeiro: Jorge Zahar. 1997.

FORELL, George W.Fé ativa no amor. 2. Ed. Trad. Geraldo Korndörfer. Porto Alegre; São Leopoldo: Concórdia; Sinodal,1985.

Fundação Catarinense de Cultura. Cartilha Patrimônio Imaterial. Secretaria de Estado de Turismo, Cultura e Esporte. Governo do Estado de Santa Catarina. s/d.

GEERTZ, Clifford. A interpretação das culturas. Rio de Janeiro: LTC, 2011.

JASPERS, Karl. Der philosophische Glaube. Zürich: Artemis Verlag, 1948.

LUTERO, Martinho. Da vontade Cativa, In: Obras Selecionadas: debates e controvérsias, II. Vol. 4. São Leopoldo; Porto Alegre: Sinodal; Concórdia, 1993. p. 11-216.

Luther, Martin.De Servo Arbitrio Mar. Lutheri ad Erasmum Roterodamum, 1525, WA 18, p. 600-787.

LUTERO, Martinho. Tratado de Martinho Lutero sobre a Liberdade Cristã Obras Selecionadas: O programa da Reforma: Escritos de 1520. São Leopoldo; Sinodal; Porto Alegre: Concórdia. 1989. Vol. 2.p. 435-463.

LUTERO, Martinho. Das Boas Obras. In: LUTERO, Martinho. Obras Selecionadas: O Programa da Reforma. Escritos de 1520. Vol. 2. São Leopoldo; Porto Alegre: Sinodal; Concórdia,1989.p. 97-170.

Luther, Martin. Von den guten werckenn, 1520, WA 6, p. 202-276. 
Luther, Martin. An die Ratherren aller Städte deutsches Lands, dass sie christliche schulen aufrichten und erhalten sollen, 1524, WA 15Parte 2.

Lutero, Martinho. Aos conselhos de todas as cidades da Alemanha para que criem e mantenham escolas cristãs. In: LUTERO, Martinho. Obras Selecionadas: Ética: fundamentos-oração-sexualidade-educação-economia. Vol. 5. São Leopoldo; Porto Alegre: Sinodal, Concórdia, 1995. p. 302-325.

MAFFESOLI, Michel. A parte do diabo: resumo da subversão pós-moderna. Trad. Clóvis Marques. Rio de Janeiro: Record, 2004. P. 91-110.

MAFFESOLI, Michel. A sombra de Dionísio: contribuição a uma sociologia da orgia. 2. Ed. Trad. Rogério de Almeida. São Paulo: Zouk, 2005.

PASSOS. João Décio. Desafios de um empréstimo epistemológico. Ciberteologia: Revista de Teologia e Cultura. Ano 5, n. 26 São Paulo: Paulinas, 2009. Disponível em: http://ciberteologia.paulinas.org.br/ciberteologia/index.php/2009/11/ Acesso em: 02 de fevereiro de 2014.

PIERUCCI, Antônio Flávio. Apresentação. In: WEBER. Max. A ética protestante e o "espírito" do Capitalismo. Trad. José Marcos Mariani de Macedo. São Paulo: Companhia das Letras, 2004.

RAYnaut, Claude. Interdisciplinaridade: mundo contemporâneo, complexidade e desafios à produção e à aplicação de conhecimentos. In: PHILIPPI JR, Arlindo; SILVA NETO, Antônio(Eds).Interdisciplinaridade em ciência, tecnologia e inovação.Barueri, SP: Manole, 2011.

RICOEUR, Paul. A memória, a história o esquecimento. Trad. Alain François. Campinas: Editora Unicamp, 2007.

Roteiros nacionais de imigração - Santa Catarina: Preservação do Patrimônio Cultural. Florianópolis; IPHAN/11. Superintendência Regional, 2008.

Superintendência Regional do IPHAN em Santa Catarina. Roteiros nacionais de imigração de Santa Catarina. Ministério da Cultura - Governo Federal,s/d.

Instituto do patrimônio Histórico Artístico Nacional. Roteiros Nacionais de Imigração - Santa Catarina: preservação do patrimônio cultural. Florianópolis: IPHAN/ 11. Superintendência Regional, 2008.

UNESCO. World Heritage Convention. Disponível em:http://whc.unesco.org/ Acesso em: 02 de fevereiro de 2014.

SCHWEIZER, Albert. Kultur und Ethik. München: Beck, 1996.

SELL, Carlos Eduardo; BRÜSEKE, Franz Josef. Mística e Sociedade. Itajaí: Universidade do Vale do Itajaí; São Paulo: Paulinas, 2006.

SELL, Carlos Eduardo. Sociologia Clássica. 4. Ed. Itajaí; Blumenau: Univali; Furb, 
2006.

SINNER, Rudolf von. Towards a Theology of Citizenship as Public Theology in Brazil.In: Religion \& Theology. 16 (2009) 181-206. Leiden: Koninklijke Brill NV,2009.

TILLICH, Paul. Theology of culture. New York: Oxford University Press, 1959.

TILLICH, Paul. The Interpretation of History. New York; London: Charles Scribner'sSons, 1936.

VATTIMO, Gianni. O fim da Modernidade: niilismo e hermenêutica na cultura pós-moderna. Trad. Eduardo Brandão. São Paulo: Martins Fontes, 2002.

WEBER, Max. Economia e Sociedade: Fundamentos da Sociologia compreensiva. Trad. Regis Barbosa; Karen Elsabe Barbosa. Brasília: Editora UNB, 1999. Vol. 2.

WEBER, Max. A ética protestante e o "espírito" do capitalismo. Trad. José Marcos Mariani de Macedo. São Paulo: Comp. das Letras, 2004.

WEstphal, Euler R. Linguagem como representação: uma breve aproximação hermenêutica. In: LAMAS, Nadja de Carvalho; JAHN, Alena Rizi Marmo(Orgs). Arte e Cultura: passos, espaços e territórios. Joinville: Editora Univille, 2012. p. 59-78.

Winkler, Michael. Bildung und Kultur: Verwirrende Grundlagen versuchsweise dargestellt. In: Manuel Fröhlich; Karsten Kenklies; Ralf Koerrenz et alli. Bildung und Kultur - Relationen. Jena: Verlag IKS Garamond, 2012, p. 13-53. 